\title{
Entrevista de Suely Rozenfeld à Physis
}

\author{
| ${ }^{1}$ Rafaela Zorzanelli | \\ ${ }^{1}$ Instituto de Medicina Social, Universidade do Estado do Rio de Janeiro. Rio de Janeiro-RJ, Brasil (rtzorzanelli@gmail.com).

Sem temor de cometer exageros, ouvir a trajetória profissional de Suely Rozenfeld é ter um testemunho vivo da história das regulaçóes dos medicamentos no Brasil. Tendo dedicado sua vida profissional a pensar “o lado B" dos medicamentos, tanto em seus trabalhos de farmacovigilância quanto em suas pesquisas - ou seja, os efeitos colaterais, o equilíbrio instável entre benefício e custo para o organismo, os riscos potenciais do uso crônico - ela traz à cena um ponto cego da relação que temos com os remédios, qual seja, a relação de quem crê no medicamento como um talismã, e não como produto envolvido em múltiplas redes de interesse (indústria farmacêutica, patentes, interesses corporativos profissionais, dentre outros).

Esta entrevista - sem pretender o rigor conceitual e os procedimentos de uma história oral ou algo semelhante - é a tentativa de reunir e registrar em um documento escrito um pouco das informaçóes e análises que a entrevistada nos traz a respeito de temas que vão desde as ações do órgão que precedeu a Agência Nacional de Vigilância Sanitária (ANVISA), a Secretaria Nacional de Vigilância Sanitária (SNVS), quanto as questóes específicas envolvidas na regulação de diferentes medicamentos-problema, como o complexo vitamínico Vitasay, o contraceptivo Norplant, os célebres antidistônicos e outros casos de interesse.

1) RZ: Você poderia nos falar um pouco a respeito de sua atuaçáo na Secretaria Nacional de Vigilância Sanitária, entre 1985 e 1987? No que esse órgão já prenunciava o que viria a ser a ANVISA, posteriormente organizada?

SR: Na década de 1980, a Secretaria Nacional de Vigilância Sanitária (SNVS) era uma das secretarias gerais ligadas diretamente ao ministro da Saúde. Era parte da 
Administração Direta do Serviço Público. Ela foi substituída pela ANVISA nos anos 2000, para a qual foram transferidas as funções de regulação, fiscalização e controle de produtos e serviços de saúde. A SNVS era composta por cinco Divisôes técnicas, quatro relacionadas a produtos (medicamentos, alimentos, cosméticos, saneantes) mais a Divisão de Portos, Aeroportos e Fronteiras. Havia ainda Divisôes de apoio, como Administração e Legislação. Fui Diretora da Divisão de Medicamentos (DIMED) entre 1985 e 1987. A equipe da SNVS, sob a chefia de Luis Felipe Moreira Lima, era muito coesa e atuava com bastante autonomia. Não levávamos em conta interesses econômicos de grupos ou de empresas. $\mathrm{O}$ foco do nosso desempenho era a proteção à saúde das pessoas.

2) RZ: Como figura atuante diretamente nesses casos, você pode rememorar um pouco sobre as controvérsias em torno do caso da Coristina e do Vitasay?

SR: Os episódios relacionados aos produtos Coristina e Vitasay fazem parte da Vigilância Pós-Registro, programa de ação que desenvolvemos na época e que está descrito no livro Epidemiologia do medicamento. ${ }^{1}$ Em resumo, o que ocorreu foi o seguinte: o antigripal Coristina, da Shering, vinha sendo comercializado com duas bulas diferentes, algumas recomendando o uso de 25 gotas e outras de 160. A partir do acolhimento de denúncia de um consumidor - que teria sofrido acidente por dormir ao volante após tomar 160 gotas - nos certificamos da irregularidade. Penalizamos a empresa com: divulgação ampla do episódio na imprensa leiga; obrigação de retirada dos frascos com posologia incorreta em todo território nacional; e análise de novos pedidos apenas após a retirada completa do produto irregular.

Já o complexo vitamínico Vitasay 10, da Dorsay, era comercializado com fórmula não autorizada pela DIMED e amplamente propagandeado na televisão pelo Pelé. Os testes laboratoriais feitos pelo Instituto Nacional de Controle de Qualidade (INCQS/Fiocruz) identificaram apenas oito dos 17 componentes da fórmula alegados na bula! A empresa foi punida com: divulgação ampla do episódio na imprensa leiga; e suspensão da propaganda nos meios de comunicação de massa. É interessante notar que a Shering era, na época, uma grande empresa multinacional, e a Dorsay, uma grande firma nacional. Açôes capazes de prejudicar os cidadãos ocorrem independentemente da natureza econômica da firma! 
3) RZ: Antidistônicos foram uma categoria de substâncias que alcançou grande entrada entre os leigos. $O$ que você poderia nos contar sobre a regulamentaçáo em torno dessas substâncias?

SR: Até onde eu sei, os antidistônicos eram comercializados apenas no Brasil. Verdadeira aberração farmacológica e clínica! $\mathrm{Na}$ sua composição estavam associados benzodiazepínico, bloqueador do sistema nervoso parassimpático e bloqueador do simpático. A dose comercializada de benzodiazepínico era baixa, e eventualmente fora da janela terapêutica. Com isso, os fabricantes escapavam do controle aplicado a psicotrópicos e entorpecentes. Os antidistônicos eram vendidos livremente, sem exigência da apresentação de receita médica. Abrimos, então, um amplo e demorado processo de consulta para rever as portarias de controle de produtos que afetam as funções do sistema nervoso central. Envolvemos mais de uma centena de entidades, incluindo Conselhos de Medicina e Farmácia, secretarias de Saúde, representantes da indústria e do comércio, e outros. O resultado foi a publicação de duas novas portarias de controle de psicotrópicos e entorpecentes (Portarias nos 27 e 28, de 1986). Nelas estava incluída a obrigatoriedade da apresentação de receita especial para a compra de antidistônicos. Após a publicação das portarias, ocorreu queda drástica das vendas, até o desaparecimento do produto do mercado. As portarias aprimoravam o controle de comercialização e prescrição e vigoraram por muito tempo, sendo substituídas mais de 15 anos depois. Outro resultado do processo de revisão da legislaçáo foi minha demissão do cargo poucos meses depois!

4) RZ: Atualmente, a questáo do uso da ayahuasca (Banisteriopsis caapi) fora de situaçóes rituais e tradicionais, e mais amplamente, de substâncias enteógenas, tem sido alvo de inúmeros debates, e sabemos que a ayahuasca não se configura na lista das substâncias proscritas. Recupere um pouco a história e os porquês em torno do endosso da ANVISA sobre o uso da ayahuasca.

SR: Há muitas décadas, a ayahuasca é planta usada em chás durante rituais de práticas religiosas, como o Santo Daime e a União do Vegetal. Em 1986, a Polícia Federal apresentou uma demanda à DIMED: ou se retirava a ayahuasca da lista de substâncias proscritas ou eles teriam que levar à prisão os praticantes 
dos rituais. O Conselho de Entorpecentes (CONFEN) se encarregou de abordar o tema. O CONFEN era um órgáo consultivo muito interessante, ligado ao Ministério da Justiça. Dele participavam representantes da Polícia Federal, juristas, psiquiatras e a própria DIMED, a quem competia deliberar. Após estudos, visitas e entrevistas com os praticantes, optou-se por excluir o Banisteriopsis caapi da lista de substâncias proscritas, a despeito de ele produzir alteraçóes no sistema nervoso central. Assinei a Portaria, e o status da ayahuasca permanece o mesmo desde então. A decisão foi embasada nos estudos que existiam sobre as alteraçóes provocadas pelo uso do chá; pela constatação do uso controlado e restrito às cerimônias; pela falta completa de ligação com as drogas ilícitas; e pela ausência de registro de danos aos usuários. Recente artigo do jornal O Globo ${ }^{2}$ conta que nos anos 1990 surgiram igrejas do Santo Daime e da União do Vegetal nos EUA, na Holanda, na Alemanha, na Espanha e no Japão, que têm hoje milhares de adeptos. Mesmo nesses países, há controvérsia sobre o status legal da planta.

\section{5) RZ: Seu nome é ligado diretamente à regulação e às disputas em torno do anticoncepcional Norplant. Poderia resumir um pouco do dilema em torno dessa substância e os conflitos em torno dela?}

SR: Norplant era a marca do implante subdérmico anticonceptivo com hormônio levonorgestrel, testado no Brasil desde os anos 1960. O "teste clínico expandido” foi autorizado em 1984 pelo então diretor da DIMED. Quando assumi, em 1985, uma médica sanitarista, feminista, Ana Regina Reis, enviou um sinal de alerta sobre a necessidade de nos debruçarmos sobre o assunto. Fomos verificar e vimos que havia mais de 3.500 mulheres com os implantes, espalhadas pelo território nacional, com perspectiva de inclusão, sem limites, de outras mais! Tratava-se de uma investigação cujas características violavam aspectos básicos dos ensaios clínicos em seres humanos, inclusive sem a assinatura das usuárias no termo de conhecimento de risco, em vigor na época. Depois de estudar o caso detalhadamente, e de reunióes com o responsável pela pesquisa e com especialistas, cancelamos a permissão para a continuidade das inserçôes. Posteriormente, $\mathrm{o}$ Conselho Federal de Medicina referendou nossa decisão. Muitas mulheres tiveram dificuldades para ter as cápsulas retiradas pelos profissionais que as inseriram. Na época, Sergio Koifman, médico sanitarista, entrevistou 175 mulheres no Rio de Janeiro. Na publicação dos resultados, ele e sua equipe 
recomendavam a retirada dos implantes de todas as mulheres. ${ }^{3} \mathrm{~A}$ investigação de Koifman apontava aumento de risco, entre usuárias do implante, de ter desordens menstruais, hipertensão arterial, graves distúrbios de peso e hipertricose. Muitas relatavam, também, alteraçóes psíquicas e biológicas importantes, que regrediam com a retirada do implante. Em 2017, pesquisadores publicaram um belo artigo, revisitando a trajetória desse contraceptivo no Brasil, até sua proibição em 1986. Segundo os autores, o caso Norplant desencadeou transformaçóes nas quais "Estilos de pensamento médico-científicos foram sacudidos e novas formas de pensar autonomia científica começaram a ser discutidas no pais". ${ }^{4}$

6) RZ: Entre 1987 e 1994, você retorna à Fiocruz como pesquisadora. Quais eram suas motivaçóes como pesquisadora, tendo adquirido tantas experiências na vigilância sanitária em saúde pública?

SR: Analisando retrospectivamente, os dois anos de trabalho na DIMED se transformaram na experiência profissional mais rica e relevante da minha vida profissional. Revelaram um aspecto da saúde pública que eu desconhecia! E ilustraram, com riqueza de detalhes, o modo como os interesses econômicos se movem e se manifestam no campo da saúde. Quando retornei à ENSP, em 1987, decidi que, dali em diante, dedicaria meu trabalho a chamar atenção sobre a necessidade de reduzir, ou de eliminar, o uso irracional dos medicamentos danosos e dos desnecessários. Fiz isso, junto com outros colegas, durante os últimos 30 anos. Criamos cursos de vigilância sanitária e estudamos alguns tipos de produtos problemáticos, sendo o primeiro deles a associação entre antitussígenos e expectorantes, num mesmo produto. Trata-se de uma "contradição farmacológica", já que a expectoração costuma ser desencadeada pela tosse!

7) RZ: Sua carreira é marcada pela atenção em formar profissionais de saúde que estejam atentos náo somente à eficácia, mas também aos efeitos adversos dos medicamentos. Você arriscaria dizer algumas palavras sobre por que, de forma geral, no Brasil, a dimensão do risco e da nocividade na ingesta de medicamentos tem menos debate do que em outros países?

SR: Não é fácil responder a essa pergunta. Do ponto de vista das bases teóricas, não me considero habilitada a analisar as diferenças entre o Brasil e outros países. 
Mas vou arriscar algumas ideias. A indústria farmacêutica é considerada, em seu conjunto, como corporação internacional com grande poder econômico e político, financiando, inclusive, campanhas eleitorais. No Brasil, há sites que descrevem políticos beneficiados, partidos, valores e financiadores de campanhas. De forma geral, as farmacêuticas acionam os mecanismos de poder - que podem incluir omissão ou deformação de informações, sedução econômica, corrupção - não apenas para obter dos órgãos de regulação atendimento às suas demandas concretas, especialmente em termos de registro. Mas para inculcar na sociedade noções, tais como sua imprescindibilidade ao longo de toda a vida dos indivíduos; sua insuspeita qualidade técnica; a legitimidade dos processos de envolvimento dos profissionais que prescrevem, incluindo benefícios materiais. Além disso, os mecanismos de poder da indústria da saúde, de forma geral, têm criado, reforçado e se beneficiado das chamadas medicalização e "medicamentalização". Esses conceitos têm a ver com o medo (real e justificado!) do adoecer e do morrer, e com o antídoto ao medo: o "preventivismo" exagerado e acrítico, cujos malefícios já vêm sendo estudados e apresentados à sociedade, como no caso das cirurgias desnecessárias de mama! Então, o debate sobre os efeitos nocivos dos medicamentos - que todos eles, sem exceção, podem apresentar - depende das características culturais e políticas de cada país. Depende do acúmulo de lutas por direitos; do grau de instrução e informação da população; da independência dos profissionais de saúde no pensar e no agir; da garantia das boas práticas de atenção médica e assistencial acumuladas historicamente.

8) RZ: Entre 1994 e 2013, você se dedicou a pesquisas em Farmacovigilância e Farmacoepidemiologia, bem como realizou seu doutorado no Instituto de Medicina Social. Nesse tempo, suas pesquisas mostram uma vasta trajetória por classes diferentes de substâncias, como os benzodiazepínicos, os anti-inflamatórios náo esteroides, a albumina e a penicilina benzatina. É possível nos dizer o que, nessas substâncias, lhe chamou a atenção como medicamentos-problema e quais eram as principais questóes envolvidas nelas, no cenário brasileiro?

SR: Alguns problemas relacionados aos medicamentos, nós abordamos em artigos na imprensa leiga, como no Jornal do Brasil e n'O Globo. O mais recente deles refere-se aos anorexígenos, "remédios para emagrecer", cuja relação risco- 
benefício é desfavorável, e cujo uso deve ser proscrito. Em termos de investigação, estudei, juntamente, com outros colegas, o uso de medicamentos em pessoas acima dos 60 anos de idade. Entre os problemas identificados, destacamos o uso prolongado de tranquilizantes (benzodiazepínicos) que podem levar a problemas graves, como quedas e fraturas. E também, o uso excessivo de produtos nessa faixa etária. O efeito somado de dois ou mais produtos pode resultar em interação danosa. Isso acontece com o uso concomitante de anti-hipertensivos e antiinflamatórios, e compromete o controle da pressão arterial. Por sinal, o uso de anti-inflamatórios, segundo estudos que fizemos com dados dos funcionários da UERJ (Estudo Pró Saúde), está associado ao aumento do número de horas trabalhadas! Já a albumina, os hormônios empregados na menopausa, a penicilina benzatina e os produtos usados no tratamento da tuberculose, pode-se dizer que são ferramentas terapêuticas importantes. Mas podem levar a gastos desnecessários; a efeitos adversos evitáveis, às vezes graves; ou à baixa eficácia terapêutica, sempre que usados fora das indicaçôes terapêuticas estabelecidas em protocolos (albumina, hormônios pós-menopausa), com técnicas ou produtos inadequados (penicilina benzatina), ou sem observância meticulosa dos efeitos adversos (tratamento antituberculose). Nos últimos anos, desenvolvemos uma linha de trabalho com pacientes hospitalizados. Aplicamos diferentes abordagens, segundo métodos empregados internacionalmente, para identificar os efeitos indesejáveis. Infelizmente, no Brasil, ao contrário de outros países, os medicamentos usados pelos pacientes internados, embora registrados nos prontuários, não são transferidos para os grandes bancos de dados nacionais. Trata-se de uma aberração, para a qual chamamos atenção há vários anos, sem sucesso!

9) RZ: Você finalizou recentemente uma estadia de dois anos dedicando-se a estudos pós-doutorais novamente no IMS. Das leituras e dos debates com os quais você dialogou nesse tempo, o que se destacou como relevante para sua pesquisa?

SR: No IMS fiz minha formação, após a graduação: residência médica, mestrado, doutorado e pós-doutorado. Mais uma vez, o acolhimento dos colegas criou um ambiente favorável ao estudo e à reflexão. Novos horizontes se abriram para mim. Desta vez no campo qualitativo, vindo a somar com minha experiência em 
Epidemiologia. Nesse período, conheci e pude aprofundar a leitura de autores como Robert Aranowitz, Jeremy Greene, Peter Gotzsche, Serge Sismondo, Abraham Verguese, Joseph Dumit, Brian Goldman, Allen Frances e outros. A partir daí, pretendo agregar novos olhares, que vão além da Clínica, da Farmacologia e da regulação sanitária. E que implicam observar os processos de introdução gradual de ideias que acabam por permear as diferentes camadas sociais, tornamse hegemônicas, e produzem resultados nem sempre percebidos como sociais. No período que estive no IMS, tive, ainda, oportunidade de estudar o banco de dados que contém informação sobre medicamentos controlados vendidos em farmácias e drogarias (Sistema Nacional de Gerenciamento de Produtos Controlados/SNGPC/ANVISA). Disso resultou uma investigação sobre uso de clonazepam (cujo nome de referência é o Rivotril ${ }^{\odot}$ ), no Estado do Rio de Janeiro. Sou muito grata aos colegas do IMS por essa oportunidade!

\section{Notas}

${ }^{1}$ LAPORTE, J.R.; TONINI G.T.; ROZENFELD, S. Epidemiologia do medicamento. São Paulo/Rio de Janeiro: Hucitec/Abrasco, 1989.

${ }^{2}$ REHEN, L.; REHEN, S. Liberdade e pesquisa. O Globo. Rio de Janeiro, 29 dez. 2016. Disponível em: < http://noblat.oglobo.globo.com/geral/noticia/2016/12/liberdade-e-pesquisa.html>.

${ }^{3}$ KOIFMAN, S. et al. Avaliação do anticoncepcional Norplant no Município do Rio de Janeiro, RJ. Brasil. Rev. Saúde Pública. São Paulo, v. 21, n. 6, p. 513-522, 1987.

${ }^{4}$ PIMENTEL, A.C.L. et al. A breve vida do Norplant ${ }^{\oplus}$ no Brasil: controvérsias e reagregaçôes entre ciência, sociedade e Estado. Ciênc. saúde coletiva. Rio de Janeiro, v. 22, n. 1, p. 43-52, 2017. 